\title{
Automized Pharmacy Using Face Authentication ${ }^{\dagger}$
}

\author{
Angel Preethi R. ${ }^{1}$, Sughasri K. ${ }^{1}$, J. Premkumar ${ }^{1, *}$ \\ 1 Department of Biomedical Engineering, School of Bio \& Chemical Engineering, Sathyabama Institute of Science \& \\ Technology, Chennai 600119 \\ * Correspondence: premkumar.biomed@sathyabama.ac.in; \\ $\dagger$ Presented at International e-Conference on Bioengineering for Health and Environment (ICBHE 2020)
}

Received: 5.07.2020; Revised: 10.07.2020; Accepted: 12.07.2020; Published: 15.07.2020

\begin{abstract}
The main objective of the work is to help the patients in the pharmacy using Automized face recognition system. Nowadays, monitoring health becomes irregular, and that is a major issue facing all patients. To overcome those irregular activities, this concept improvised medical tool such that automized pharmacy is to help the patients to keep up their day to day pills intake process with superior technology and by this process implementing face authentic and mobile integration which gives a more convenient way to keep their medical prescriptions in a periodic manner. The system can also be useful in hospitals where the number of patients is more, and it is difficult to remember the medicine and dosage by the staff. So this system with some updates can also be used in hospitals. The problems such as 1) maintaining the regularity of prescribed dosage is difficult to be remembered in a busy schedule.

2) Remembering the name of medicine to be taken is really difficult. Therefore, the growing need and urgency for in-home healthcare devices and technologies in order to provide patients with electronic tools to support medication self-management is addressed by the above advancement in today's technology.
\end{abstract}

Keywords: automized pharmacy; face authentication; dosage; healthcare; medical prescription.

(C) 2020 by the authors. This article is an open-access article distributed under the terms and conditions of the Creative Commons Attribution (CC BY) license (https://creativecommons.org/licenses/by/4.0/).

\section{Funding}

This research received no external funding.

\section{Acknowledgments}

This research has no acknowledgment.

\section{Conflicts of Interest}

The authors declare no conflict of interest. 